Archived version from NCDOCKS Institutional Repository http://libres.uncg.edu/ir/asu/

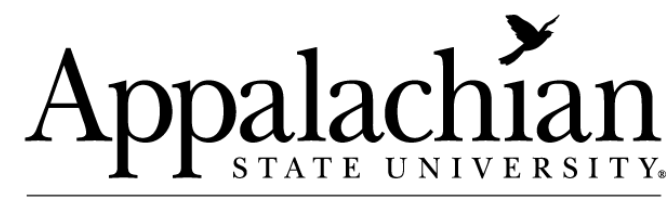

B O O N E, NORT H C A R O L I A

\section{Predictors Of Intention To Travel To Cuba Across Three Time Horizons: An Application Of The Theory Of Planned Behavior}

\author{
By: Evan J. Jordan, B. Bynum Boley, Whitney Knollenberg, and Carol Kline
}

\begin{abstract}
As the relationship between Cuba and the United States evolves, many Americans are entertaining the idea of travel to Cuba. This study used the Theory of Planned Behavior (TPB) to examine predictors of US residents' intentions to travel to Cuba across three time horizons: 1 year, 5 years, and 10 years. TPB constructs were administered to a cross-sectional panel of US residents. Results varied by time horizon, with US residents' negative attitudes toward Cuba having a positive and significant influence on their intention to visit Cuba within one year. This finding suggests that some US residents match Plog's Allocentric profile of tourists and that the current "rough edges" of Cuba are what attract them to travel in the short rather than long term. Findings from this study provide baseline data that is valuable for Cuban and American tourism organizations, should the US market become more accessible.
\end{abstract}

Jordan, E. J., Bynum Boley, B., Knollenberg, W., \& Kline, C. (2018). Predictors of Intention to Travel to Cuba across Three Time Horizons: An Application of the Theory of Planned Behavior. Journal of Travel Research, 57(7), 981-993. https://doi.org/10.1177/0047287517721370. Publisher version of record available at: https://journals.sagepub.com/doi/full/10.1177/0047287517721370 


\title{
Predictors of Intention to Travel to Cuba across Three Time Horizons: An Application of the Theory of Planned Behavior
}

\author{
Evan J. Jordan', B. Bynum Boley², Whitney Knollenberg', \\ and Carol Kline
}

\begin{abstract}
As the relationship between Cuba and the United States evolves, many Americans are entertaining the idea of travel to Cuba. This study used the Theory of Planned Behavior (TPB) to examine predictors of US residents' intentions to travel to Cuba across three time horizons: I year, 5 years, and 10 years. TPB constructs were administered to a cross-sectional panel of US residents. Results varied by time horizon, with US residents' negative attitudes toward Cuba having a positive and significant influence on their intention to visit Cuba within one year. This finding suggests that some US residents match Plog's Allocentric profile of tourists and that the current "rough edges" of Cuba are what attract them to travel in the short rather than long term. Findings from this study provide baseline data that is valuable for Cuban and American tourism organizations, should the US market become more accessible.
\end{abstract}

\section{Keywords}

Cuba, Theory of Planned Behavior, travel time horizons, travel intention, psychographics

\section{Introduction}

Travel from the United States to Cuba has recently become more feasible with the resumption of full diplomatic relations between the two countries in 2015 (White House 2016). With the warming political climate, many travel companies have begun to explore the possibility of bringing US tourists directly to Cuba. This became a reality in May 2016 with the first cruise ship in decades embarking from the United States for the port of Havana, Cuba, with around 700 passengers, marking a significant step toward normalized travel (Ramos and Shoichet 2016). The US government has also authorized six US airlines to begin nonstop service to Cuba (Davis 2016). However, travel restrictions remain in place, and according to the US Embassy in Havana, only travelers from the 12 specific groups including family trips, business travel, research and educational activities, and humanitarian projects may travel to Cuba without the need for a Special License (US Embassy 2016). With relations warming between the United States and Cuba, the potential for normalized travel between the two countries has become increasingly likely even though the recent election of a new US presidential administration has added some uncertainty about the positive trajectory of Cuban-American relations (Whitefield 2017). As the trade and travel embargo has been in place since the early 1960s, little is known about the potential market for outbound travel from the United States to Cuba.

The Cuban economy has undergone significant changes in recent years, and international tourism has played an increasingly important role since leadership shifted from Fidel to Raul Castro in 2008 (Hingtgen et al. 2015). According to the World Bank, Cuba hosted nearly 3 million international tourist arrivals in 2014, up from about 2 million international arrivals in 2004 and an increase of 700,000 since 2008 (World Bank 2016). The World Travel \& Tourism Council estimates that tourism directly and indirectly contributed to more than $10 \%$ of Cuba's GDP and supported

\footnotetext{
'School of Community Resources and Development, Arizona State University, Phoenix, AZ, USA

${ }^{2}$ Department of Natural Resources Recreation and Tourism (NRRT), Warnell School of Forestry and Natural Resources, University of Georgia, Athens, GA, USA.

${ }^{3}$ Parks, Recreation \& Tourism Management, North Carolina State University, Raleigh, NC, USA

${ }^{4}$ Walker College of Business, Appalachian State University, Boone, NC, USA
}

Corresponding Author:

Evan J. Jordan, School of Community Resources and Development, Arizona State University, 4I I N Central Ave, Suite 550, Phoenix, AZ 85004, USA

Email: evan.jordan@asu.edu 
just over 9\% of Cuba's total jobs in 2015 (World Travel \& Tourism Council 2016). Economists predict that the warming of US-Cuba relations may generate a large influx of US tourists, which could lead to supply shock, whereby an adjustment period would be needed for Cuba to accommodate the significant rise in visitation (Romeu 2014). The growth of international tourism and potential influx of US tourists could be a boon for the Cuban economy and businesses that serve travelers.

Despite the potential for increasing Cuba's share of the US outbound tourism market, little is known about US residents' perceptions of Cuba as a tourism destination or what could influence their decisions to travel there. Therefore, the purpose of this study was to utilize the Theory of Planned Behavior (TPB) (Ajzen 1991) to examine predictors of US residents' intentions to travel to Cuba across three time horizons: one year, five years, and ten years. The TPB postulates that individuals' attitudes, perceived behavioral control, and subjective norms about a behavior predict intentions to engage in that behavior (Ajzen 1991). Previous research in the tourism field has consistently found the TPB to have utility in predicting engagement in actual behaviors based on behavioral intentions in the marketing and consumer behaviors realm (Bianchi, Milberg, and Cúneo 2017; Han, Hsu, and Sheu 2010; Lam and Hsu 2004). The three travel time horizons used to measure intentions to travel to Cuba are novel for exploring whether there are differences in those who wish to travel sooner or later, especially given the uncertainty of travel to Cuba from the United States due to changing regulations, as well as potential changes to the Cuban travel product. Moreover, it is precisely the historical political tension between the two nations which could likely influence the social norms and attitudes of Americans, as well as the influence of the trade embargo on Americans' perceived behavioral control, that renders the use of TPB to explore US residents' intention to travel as relevant. Indeed, this study adds to the growing body of literature on travel to controversial, contested, forbidden, or fringe destinations.

Some controversial destinations are considered such because of established trade ethics, or rather the aversion to doing business with nations whose officials are known for human rights violations; others are partitioned states with differing political views (Webster and Timothy 2006). Hannam (2013, p. 178) explored the "geopolitical uncertainties" in China and India and found accounts of tourism from one country to the other to be "ambivalent at best" because the historical, cultural, economic, and religious perceptions of the other shape travelers' experiences. Additionally, when national regimes alter their political stance, the economic landscape at the local level can allow more entrepreneurial endeavors from its citizens, which can result in unique authentic tourism experiences or, to the contrary, increased commercialization (Hingtgen et al. 2015).

The anticipated changes in the Cuban travel product have been the source of many popular press articles and blog posts focused on "seeing Cuba before it changes" (N. Fleischner 2016; Telegraph 2016). An understanding of attitudes, perceived behavioral control, and subjective norms of US residents about potentially traveling to Cuba could be valuable for those intending to market their products or services to potential travelers from a new market region. Perhaps different marketing messages are needed based upon the type of tourists and their intentions to travel in Cuba within the next year, 5 years, or 10 years. This type of analysis is also of theoretical interests because most academic research has applied the TPB to single travel time horizons with the objective of predicting behavioral intention in the near future. Additionally, the unique political and geographical relationship between Cuba and the United States has the potential to reveal that the antecedents of the TPB (e.g., attitudes, subjective norms, and perceived behavioral control) carry different weights across different time horizons. The paper continues with a brief review of the TPB and hypotheses to be tested.

\section{Literature Review}

\section{The Theory of Planned Behavior}

The TPB is an extension of the Theory of Reasoned Action (TRA), originally developed by Fishbein and Ajzen (1977). Both theories are frameworks for understanding the process by which an individual engages in a behavior (Ajzen 1991). While the TRA focused on attitudes and subjective norms as predictors of behavioral intention, the TPB includes perceived behavioral control as an additional predictor (Madden, Ellen, and Ajzen 1992). Myriad studies within and without the social science realm have utilized TPB to examine behaviors from smoking cessation (Norman, Conner, and Bell 1999) to choice of leisure activity (Ajzen and Driver 1992), with wide support for the notion that behavioral intent is an accurate predictor of actual behavior (Armitage and Conner 2001). Researchers have proposed a variety of extensions to the TPB, including added elements of belief salience, past behavior and habit, self-efficacy, moral norms, self-identity, and affect (Conner and Armitage 1998). Despite these many proposed extensions, support remains for the simple TPB model including attitudes, subjective norms, and perceived behavioral control as predictors of behavioral intentions (Bianchi, Milberg, and Cúneo 2017; Lee and Back 2008). There is a growing body of tourism and leisure research that has applied TPB in its original and extended forms (Han and Hyun 2017; Kaplan et al. 2015; Ye et al. 2017), many of which have explored intention to travel to various destinations (Bianchi, Milberg, and Cúneo 2017; Hsieh, Park, and McNally 2016; Jalilvand and Samiei 2012; Yamada and Fu 2012). Some of the most recent extensions of the TPB include adding tourists' environmental values (Han 2015) and moral concern (M.-F. Chen and Tung 2014) to predict intentions to use green/environmentally friendly hotels. Another extension of the TPB has been to predict tourists' use of sharing 


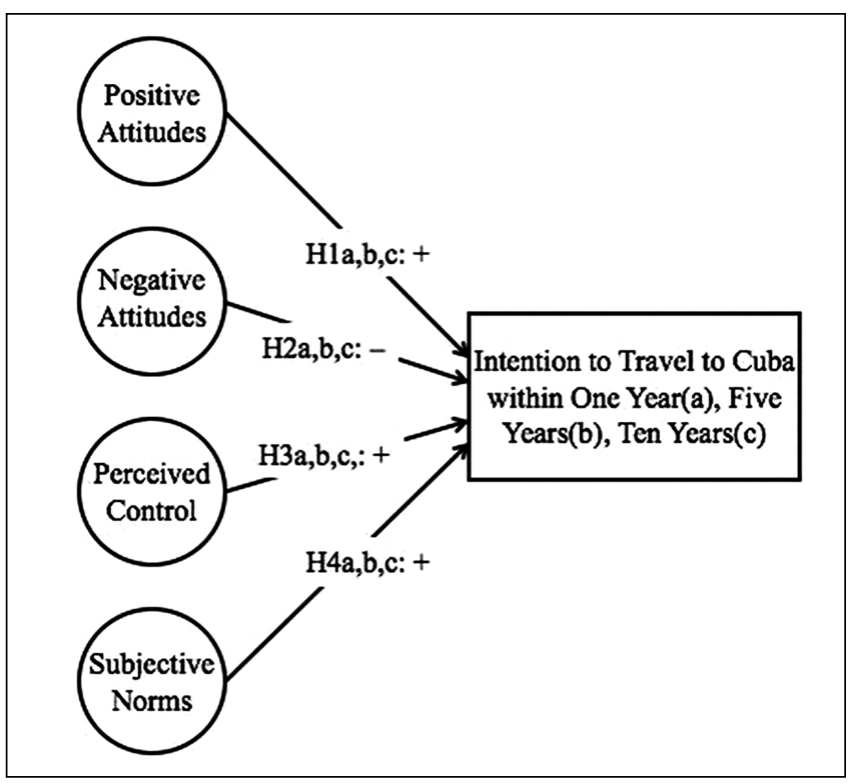

Figure I. Study model with hypotheses.

economy services such as bike sharing on holiday (Kaplan et al. 2015), ride-sharing services such as Uber (A. Fleischer and Wåhlin 2016), and short-term vacation rentals such as Airbnb (Kjeldsen and Pedersen 2016).

This study seeks to modify the TPB in two specific ways. First, rather than focus on intentions to travel to Cuba at one point in time, we separate behavioral intentions into three time periods (within the next year, 5 years, and 10 years). This modification provides the ability to test the strength and order of the TPB antecedents (e.g., attitudes, social norms, and perceived behavioral control) over the three time frames. Previous studies suggest that temporal distance influences perceptions of future events (Liberman, Sagristano, and Trope 2002). For example, people are often more confident and take on greater risk when considering events in the distant, rather than near, future (Gilovich, Kerr, and Medvec 1993). Such findings indicate that potential visitors' intentions to travel may change over time. The second modification is splitting the attitudinal construct into positive attitudes and negative attitudes. Positive and negative attitudes were separated into two question groups rather than measured with semantic differentials, as attitude theorists have suggested that separation of positive and negative attitudes more accurately reflects the evaluative processes individuals use in cognitive decision-making processes (Alexandrov 2010; Cacioppo and Berntson 1994). A graphical representation of the proposed study model with hypotheses is presented in Figure 1.

The first antecedent in the TPB model is attitudes. Attitudes are the positive or negative evaluations of a given behavior (Ajzen 1991). Individuals may have varying degrees of positive or negative attitudes toward the performance of a behavior. Positive attitudes toward a behavior have a positive relationship with intention to engage in that behavior, and negative attitudes toward a behavior have a negative relationship with intention to engage in that behavior (Ajzen 1991). Attitudes toward a tourism destination are generally perceived through a set of attributes about that destination, such as excitement or fear, and are similar in many ways to destination image (Baloglu 2000; Dolnicar and Grün 2013; Stylos et al. 2016). There is limited research examining the attitudes of US residents' general attitudes toward Cuba as a travel destination. Past research has shown that US residents' attitudes toward Cuba have been generally negative, although there is little evidence that there is a perception of threat or danger from Cuba as a country (Mayer 2001). The large Cuban-American population living in the United States has had a significant influence over ties between the two countries over the past sixty years, and recent polls have shown that many Cuban-Americans are warming to the idea of a closer relationship between the two countries (Whitefield 2015). Recent studies have also shown an increase in the general US population's support of lifting the trade and travel embargo on Cuba (Rampersad 2014). While research about US residents' attitudes toward Cuba as a country has been limited, there is even less research exploring US residents' attitudes toward Cuba as a travel destination. However, researchers have shown positive attitudes to be linked with intention to travel (Lam and Hsu 2006), and it is likely that negative attitudes have a contrasting linkage, as the perception of risk and uncertainty have previously been found to play an important role in intention to travel (Quintal, Lee, and Soutar 2010). Therefore, it is posited that US residents' positive and negative attitudes will have opposite, significant relationships with their intentions to travel to Cuba across the three time horizons of 1 year, 5 years, and 10 years. The integration of various temporal distances has not yet been applied in the context of TPB and tourism and, therefore, the following hypothesis were shaped by the existing theoretical support for attitudes, perceived behavioral controls, and subjective norms in the context of travel intention.

Hypothesis 1a: There is a direct positive relationship between positive attitudes and intention to travel to Cuba within one year.

Hypothesis $1 b$ : There is a direct positive relationship between positive attitudes and intention to travel to Cuba within five years.

Hypothesis 1c: There is a direct positive relationship between positive attitudes and intention to travel to Cuba within ten years.

Hypothesis 2a: There is a direct negative relationship between negative attitudes and intention to travel to Cuba within one year.

Hypothesis 2b: There is a direct negative relationship between negative attitudes and intention to travel to Cuba within five years. 
Hypothesis 2c: There is a direct negative relationship between negative attitudes and intention to travel to Cuba within ten years.

The second antecedent within the TPB model is perceived behavioral control. Perceived behavioral control is the belief an individual holds about how easy or difficult it would be for them to engage in a given behavior (Ajzen 1991). Tourism researchers have shown perceived behavioral control to be an accurate predictor of intentions to travel to varying destinations (Hsieh, Park, and McNally 2016; Lam and Hsu 2006). The perception of control over a behavior can be based on a variety of variables depending on the behavior in question. An individual's perceived behavioral control over purchasing a product at the store will likely involve having the financial resources available to make the purchase, having the time to go to the store, and having a way to get there. Perceived behavioral control is perhaps the most intriguing element of the TPB in the context of travel to Cuba from the United States. Recent policy changes have increased the categories of permissible travel between the countries, and as a result more travel services have become available for potential US-based travelers interested in visiting Cuba. These include Carnival Cruise Lines' launch of their Fathom ships featuring "person-to-person" travel (Carnival Cruise Lines 2016) and the opening of commercial flights from the United States to Cuba. The media coverage of these events has put a spotlight on the new opportunities for travel to Cuba; however, the United States' travel embargo to Cuba remains in place (US Embassy 2016). For potential US-based visitors, the change in policy and resultant opportunities for new travel experiences may result in greater perceived behavioral control over future travel to Cuba. This change creates an added element of perceived behavioral control that goes beyond that of previous studies within the tourism realm (Sparks 2007). For these reasons, it is posited that there will be a significant and positive relationship between perceived behavioral control and intention to travel to Cuba across the three time horizons of 1 year, 5 years, and 10 years.

Hypothesis 3a: There is a direct positive relationship between perceived behavioral control and intention to travel to Cuba within one year.

Hypothesis 3b: There is a direct positive relationship between perceived behavioral control and intention to travel to Cuba within five years.

Hypothesis 3c: There is a direct positive relationship between perceived behavioral control and intention to travel to Cuba within ten years.

The last antecedent within the TPB model is subjective norms. Subjective norms are beliefs about how those people that an individual cares about would approve or disapprove of a given behavior (Ajzen 1991). A great deal of research has shown subjective norms to be an accurate predictor of travel intentions, with those behaviors that are perceived as something that would be approved by peer groups positively related to intention to engage in those behaviors (Lam and Hsu 2006). Those behaviors that are perceived as something that would be disapproved of by peer groups are negatively related to intention to engage in those behaviors (Yamada and $\mathrm{Fu}$ 2012). Little to no research has explored subjective norms as they relate to Cuba or travel to Cuba. Subjective norms are expected to carry significant weight in US residents' intentions to travel to Cuba based upon the polarizing nature of the political relationship between the two countries. With US residents holding strong feelings toward the cessation or continuation of the trade embargo with Cuba, it is expected that the subjective norms toward traveling to Cuba will have a significant and positive relationship with intention to travel to Cuba across the three time horizons of 1 year, 5 years, and 10 years.

Hypothesis 4a: There is a direct positive relationship between subjective norms and intention to travel to Cuba within one year.

Hypothesis 4b: There is a direct positive relationship between subjective norms and intention to travel to Cuba within five years.

Hypothesis 4c: There is a direct positive relationship between subjective norms and intention to travel to Cuba within ten years.

\section{Tourism in Cuba}

The tourism industry in Cuba has changed a great deal over the last 65 years, and if unrestricted travel between the United States and Cuba is allowed in the future, it will likely change a great deal more. Prior to Fidel Castro's rise to power in Cuba and the subsequent travel and trade embargo enacted by the US Government, Cuba was a popular travel destination for many US residents throughout most of the 1950s. During that period, development happened mostly through foreign investment, as the Cuban government allowed casino development in hotels that secured significant investments (Schwartz 1997). During the beginning of the Castro era, tourism was discouraged and visitation to Cuba was reduced to a trickle (Padilla and McElroy 2007). More recently, the tourism industry has blossomed. After the fall of the Soviet Union in 1991, Cuba struggled economically and saw a significant decline in GDP for several consecutive years. As many countries with natural tourism resources like sand, sun, and sea do, Cuba turned to tourism as an economic necessity. Foreign investment in tourism infrastructure and superstructure was encouraged, and US dollars were allowed to circulate in the economy (until 2004), eventually becoming the currency in which many businesses conducted their transactions (Holan and Phillips 1997). These policy changes set the stage for the legalization of many small tourism-related private enterprises; for example, 
Cubans can now rent out rooms to tourists and establish small restaurants within their own homes (Sanchez and Adams 2008). Changes that have occurred over the past 25 years have led to increased visitation by travelers from across the globe, and set the stage for continued change as a tourism destination into the future.

As the tourism industry has changed and adapted to the sociopolitical climate over the past 65 years, it is expected that it will continue to do so in the future. Unrestricted travel from the United States to Cuba has the potential to change both the tourism product and the sense of place of Cuba. A variety of popular media outlets have recently published stories discussing the desire of many travelers to visit Cuba before "Americans ruin it" (Orsi 2015). The potential changes to Cuba as a travel destination could alter its appeal for both adventurous tourists (allocentrics) and tourists who prefer to stay within their comfort zone (psychocentrics) (Plog 2001). Although many factors contribute to travelers' choice of travel destinations (Ekinci, Sirakaya-Turk, and Preciado 2013; Jacobsen and Munar 2012; Tham, Croy, and Mair 2013), psychographic classifications such as Plog's (2001) provide a simple way to group potential travelers for this study's purposes. With the possibility of change on the horizon for Cuba as a travel destination, attitudes, perceived behavioral control and subjective norms toward traveling to Cuba are expected to have different effects on US travelers' intent to travel to Cuba within various timelines in the future. Behavioral intentions within the traditional TPB model do not normally place a time horizon on the intent to participate in the behavior of interest. With the increasingly stronger relationship between Cuba and the United States and the ensuing potential for changes to the Cuban travel product, it was deemed of interest to partition out the US travel markets' intention to travel to Cuba by near future (1 year), 5 years, and 10 years. Although researchers have shown that the relationships between intentions and actual behaviors vary by time horizon, there is a lack of previous research examining how relationships within the TPB vary based on the time in which the individual intends to participate in a given behavior (Morwitz 1997). Therefore, it is of specific interest to see how the relationships tested in hypotheses $1-4$ vary across the three time horizons.

\section{Methods}

To address the lack of knowledge about potential US residents traveling to Cuba, a cross-sectional study of a sample of US residents was conducted in April 2016. Data were collected from residents of the United States using an online panel provided by Issues and Answers, a global market research firm. Online panel data has become commonplace in the tourism research realm, and many studies have found such data to be reliable and lacking in response bias that is common to other data collection methods (Boley, Magnini, and Tuten 2013; Nunkoo and So 2016). An online survey created in Qualtrics was made available to residents of the United States 18 years of age and older, who had traveled at least 50 miles from home in the past year for business or pleasure, and who had a household income of $\$ 50,000$ or more. These criteria were used to tailor the sample toward US residents who are active travelers. In total, 1,122 individuals started the online survey. Three hundred seventy respondents were removed either because of their income and travel characteristics not meeting the above criteria or large portions of missing data within their responses. The deletions resulted in a usable sample of 758 respondents.

Researchers completed a literature review of past studies utilizing the TPB in tourism context to explore how previous studies measured attitudes, subjective norms, perceived behavioral control, and intention (Dolnicar and Grün 2013; Han, Hsu, and Sheu 2010; Hsu and Huang 2012; Lam and Hsu 2004, 2006). Questions were adapted from the aforementioned studies to measure each construct of interest within the specific context of traveling to Cuba. Table 1 provides an overview of all of the items used to measure each construct. All questions were measured using "agreement with" statements on a 7-point Likert-type scale ranging from 1 (strongly disagree) to 7 (strongly agree), with the exception of intention to travel to Cuba, which was measured using likelihood as scale anchors ranging from 1 (not at all likely) to 7 (very likely). A 7-point Likert-type scale was chosen over a 5-point scale because of the increased variance 7-point scales provide, as well as 7-point scales being found to reduce interpolation and to be well suited for electronic surveys (Finstad 2010). These questions were part of a 177-item questionnaire that assessed demographics, past travel experience, use of social media, image, and activities engaged in while traveling. Because a single source self-report survey was used in data collection for this study, there was the potential for common method bias to influence the findings. To determine whether common method bias was present in the survey items used in this study Harman's (1967) onefactor test was administered (Podsakoff et al. 2003) and the data revealed that a single factor was not extracted from those items. This indicates that common method bias is not present in the variables examined in this study.

Prior to testing the theoretical model, a series of exploratory factor analyses (EFA) and a confirmatory factory analysis (CFA) were conducted to determine appropriate factor structure, purify the measures, and maximize internal consistency as well as convergent and discriminant validity (Raubenheimer 2004). EFAs were conducted in the IBM SPSS Statistics software package, while CFAs were conducted in the Lavaan package (Rosseel 2012) in the R software environment for statistical computing and graphics. The number of suitable factors were determined using eigenvalue $>1$ and scree-plot point of inflection criteria. The EFA of the attitude items produced a two-factor solution, with several items being removed for not loading onto any factors $(<0.4)$ as well as for loading onto more than one factor $(<0.4)$ 
Table I. Items in Each Construct Pool.

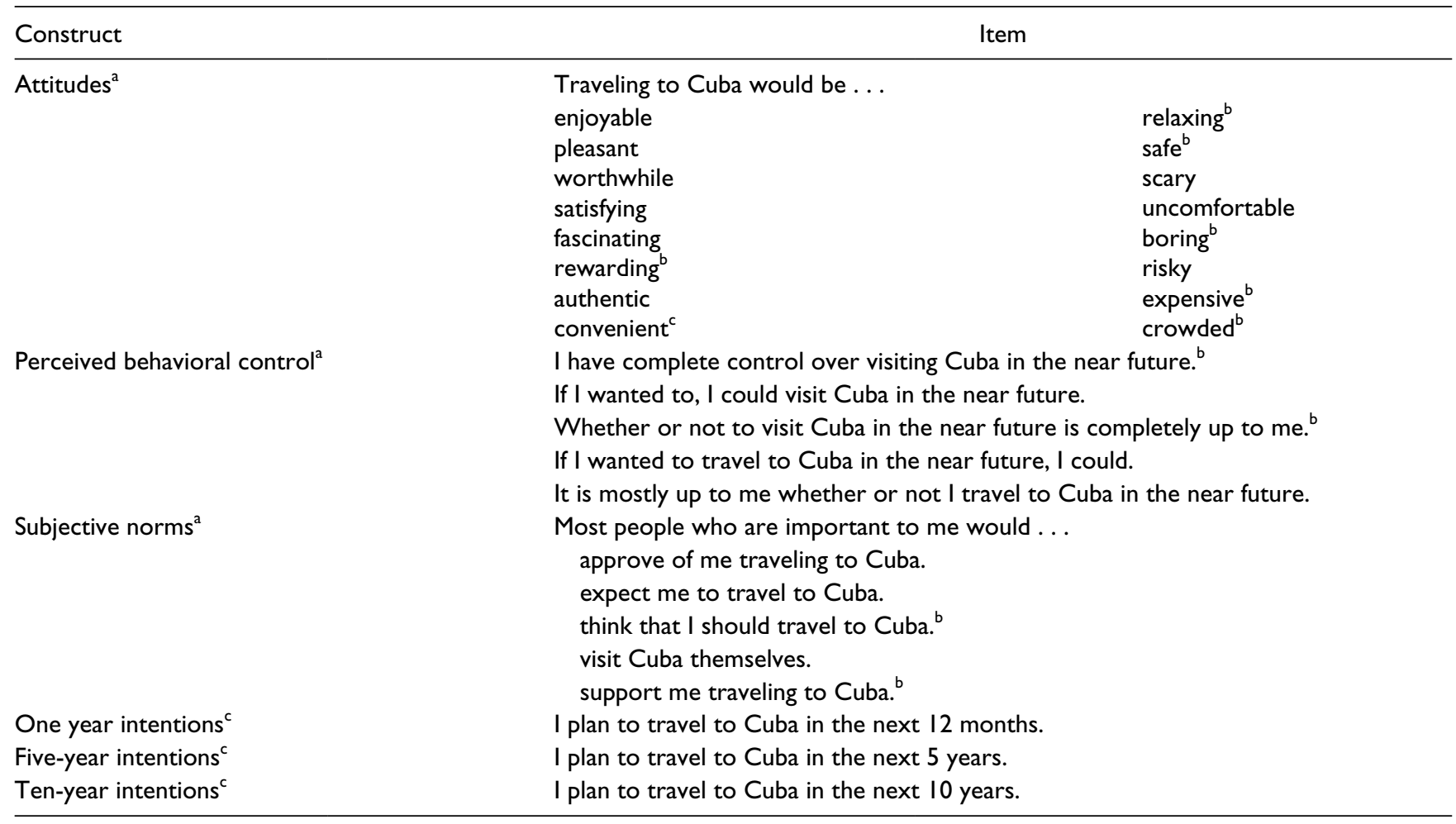

Note: Items were used from the following studies: (Dolnicar and Grün 2013; Han, Hsu, and Sheu 20I0; Hsu and Huang 20I2; Lam and Hsu 2004, 2006).

a. Scale: I = strongly disagree to 7 = strongly agree.

b. Item deleted through scale purification process.

c. Scale: I = not at all likely to $7=$ very likely.

(J.S. Chen and Hsu 2001). The EFAs of perceived behavioral control and subjective norms both produced a single-factor solution, with each item loading onto a single factor. A CFA revealed further ways to improve the reliability and validity of the measurement items. As suggested by Hair et al. (2010), several items were removed because of $R$-squared values of less than .5, as well as cross-loading items and error variances revealed by LaGrange Multiplier tests. This resulted in a parsimonious measurement model composed of six positive attitude items, three negative attitude items, three perceived behavioral control items, and three subjective norms items. Descriptive statistics of the measurement model are presented in Table 2 . Tests of scale reliability and validity and model fit statistics are provided in the results section. Univariate descriptive statistics for the dependent variables in the study are provided in Table 3.

\section{Results}

\section{Sample Profile}

Of the 758 respondents sampled, $54 \%$ were female and $46 \%$ were male. The average age of respondents was 51 years. The greatest portion of respondents $(33.9 \%)$ had an annual household income before taxes between $\$ 70,000$ and
$\$ 99,000$, while $30.2 \%$ had a household income between $\$ 50,000$ and $\$ 69,000,24.4 \%$ had a household income of between $\$ 100,000$ and $\$ 149,999$, and $11.5 \%$ had a household income higher than $\$ 150,000$. Just over $79 \%$ of respondents identified themselves as white or non-Hispanic Caucasians with $7.4 \%$ identifying themselves as Black or African American, 5.8\% as Hispanic or Latino, 5.1\% themselves as Asian, and $2.5 \%$ as another race or ethnicity. A majority of respondents $(63.2 \%)$ had earned a bachelor's degree or higher, while $16.4 \%$ indicated they had some college, $10.9 \%$ responded they had an associate's or technical degree, and $9.2 \%$ indicated they had a high school diploma or GED. In terms of previous travel experience, a majority of respondents (59.1\%) took between 2 and 5 overnight trips per year. There were a few frequent travelers that took 6 to 10 overnight trips per year $(11.9 \%)$ and 10 overnight trips per year (9.4\%). Only $19.7 \%$ of the respondents indicated they take approximately one overnight trip per year. Finally, in terms of Spanish language ability, $54.5 \%$ of respondents indicated they had no ability to speak Spanish. For those with some Spanish language skills, $27.8 \%$ identified themselves as novice Spanish speakers, 9.3\% identified themselves as intermediate Spanish speakers, 5.8\% identified themselves as expert (native) Spanish speakers, and 2.6\% identified themselves as expert (nonnative) Spanish speakers. 
Table 2. Confirmatory Factor Analysis of the Measurement Model.

\begin{tabular}{|c|c|c|c|c|}
\hline & Mean & $\begin{array}{l}\text { Standardized } \\
\text { Factor Loadings }\end{array}$ & $\begin{array}{c}\text { Cronbach's } \\
\text { Alpha }\end{array}$ & AVE \\
\hline Positive attitudes & & & .97 & $84 \%$ \\
\hline Enjoyable & 4.49 & .93 & & \\
\hline Pleasant & 4.49 & .93 & & \\
\hline Worthwhile & 4.60 & .96 & & \\
\hline Satisfying & 4.53 & .96 & & \\
\hline Fascinating & 4.87 & .89 & & \\
\hline Authentic & 4.97 & .77 & & \\
\hline Negative attitudes & & & .89 & $74 \%$ \\
\hline Scary & 4.34 & .89 & & \\
\hline Uncomfortable & 4.28 & .86 & & \\
\hline Risky & 4.43 & .83 & & \\
\hline Perceived behavioral control & & & .90 & $77 \%$ \\
\hline If I wanted to, I could visit Cuba in the near future. & 4.79 & .86 & & \\
\hline If I wanted to travel to Cuba in the near future I could. & 4.97 & .95 & & \\
\hline It is mostly up to me whether or not I travel to Cuba in the near future. & 5.06 & .81 & & \\
\hline Subjective norms & & & .92 & $78 \%$ \\
\hline $\begin{array}{l}\text { Most people who are important to me would approve of me traveling to } \\
\text { Cuba }\end{array}$ & 4.27 & .87 & & \\
\hline $\begin{array}{l}\text { Most people who are important to me would expect me to travel to } \\
\text { Cuba }\end{array}$ & 3.60 & .89 & & \\
\hline Most people who are important to me would visit Cuba themselves & 3.66 & .90 & & \\
\hline
\end{tabular}

Table 3. Descriptive Statistics of Intention to Travel Time Horizons.

\begin{tabular}{lcc}
\hline Intentions & Mean & SD \\
\hline I plan to travel to Cuba in the next I2 months & 2.62 & 1.82 \\
I plan to travel to Cuba in the next 5 years & 2.92 & 1.83 \\
I plan to travel to Cuba in the next 10 years & 2.53 & 1.52 \\
\hline
\end{tabular}

\section{Scale Reliability and Validity}

Tests of univariate normality were conducted prior to model estimation to meet assumptions required for conducting CFA and structural equation models (SEM); cutoff values for 2.0 and 7.0 for skewness and kurtosis were used respectively (Curran, West, and Finch 1996). All variables used in the analysis met skewness and kurtosis requirements. Multivariate normality was assessed via the Henze-Zirkler multivariate normality test (Henze and Zirkler 1990; Mecklin and Mundfrom 2004). The Henze-Zirkler test revealed the data to be not multivariate normal $(\mathrm{HZ}=2.51, \mathrm{p}<.05)$. However, according to Kline (2010) tests of multivariate normality are limited by the fact that very small departures from normality often result in statistically significant results in large samples. Therefore, univariate normality was deemed sufficient to proceed with CFA and SEM. All CFA and SEM models were conducted using the maximum likelihood estimator.

Prior to testing the proposed hypotheses using structural equation modeling, a CFA was performed to assess reliability and validity of study constructs and to assess model fit
(Kline 2010). Model fit was determined based upon a battery of widely used absolute and incremental indices of model fit including chi-square $\left(\chi^{2}\right)$, comparative fit index (CFI), Tucker-Lewis Index (TLI), root mean square error of approximation (RMSEA), and standardized root mean square residual (SRMR) (McDonald and Ho 2002). The $\chi^{2}$ value is presented despite its sensitivity to sample sizes greater than 200. Criteria used to determine "good fit" for CFA and subsequent SEM were CFI >.9, TLI >.9, RMSEA $<.07$, and SRMR $<.07$ to minimize the risk of Type I and Type II error (F. Chen et al. 2008; Hu and Bentler 1999; MacCallum, Browne, and Sugawara 1996). Fit of the measurement model was good $\left(\chi^{2}[84]=360.14, p=0.000\right.$, $\mathrm{CFI}=.976, \mathrm{TLI}=.971, \mathrm{RMSEA}=.066[95 \% \mathrm{CI}=.059-.073]$, $\mathrm{SRMR}=.035)$, with all fit statistics falling within the acceptable range.

CFA was also used to assess construct validity, including convergent, discriminant, and nomological validity. Convergent validity was tested using factor loadings, average variance explained (AVE) of each construct, and reliability. According to Hair et al. (2010), to achieve convergent validity all factors should have loadings of at least 0.5 and be significant, the AVE should be higher than $50 \%$, and Cronbach's alpha values should be greater than 0.7. The values presented in Table 2 indicate all tests of convergent validity meet the aforementioned requirements. Discriminant validity was tested by comparing the AVE of constructs to the squared correlation between construct pairs (Hair et al. 2010). All constructs meet the requirement 
Table 4. Correlations and Squared Correlations between Model Constructs.

\begin{tabular}{lcccc}
\hline & PA & NA & PC & SN \\
\hline Positive attitudes (PA) & $84 \%$ & 0.27 & 0.17 & 0.61 \\
Negative attitudes (NA) & -0.52 & $74 \%$ & 0.03 & 0.26 \\
Perceived behavioral control (PC) & 0.41 & -0.18 & $77 \%$ & 0.18 \\
Subjective norms (SN) & 0.78 & -0.51 & 0.43 & $78 \%$ \\
\hline
\end{tabular}

Note: All correlations are significant at $p<.05$. The diagonal line represents average variance explained (AVE) by each construct. Numbers below the diagonal line are correlations and numbers above the line are squared correlations.

that AVE should be higher than the squared correlation between constructs (Table 4). Nomological validity was tested by estimating correlations between constructs (Hair et al. 2010) (Table 4). Constructs should only significantly correlate with other constructs suggested by theory. The negative correlations between negative attitudes and all other constructs, as well as the positive correlations between all other constructs in the model indicate that the scales have nomological validity. This battery of tests indicates that the measurement model possesses construct validity, and allows for the analysis to proceed to the testing of the structural model.

\section{Structural Equation Modeling}

Hypotheses were tested through the estimation of three structural models. Fit of the structural models was assessed using the same battery of fit statistics as CFA. In the first model, the dependent variable was intention to travel to Cuba in 1 year, in the second model, the dependent variable was intention to travel to Cuba in 5 years, and in the third model the dependent variable was intention to travel to Cuba in 10 years. Those survey respondents who indicated that they planned to travel to Cuba within one year (i.e., answered 5 or greater) were removed from 5-year and 10-year models, and those who indicated that they planned to travel to Cuba within 5 years were removed from the 10 -year model. This was done to ensure each model examined the predictors of intention to travel to Cuba at the earliest likely travel time horizon indicated by respondents. This also helps mitigate the possibility that respondents viewed a dependency between travel time horizons. The structural models revealed good fit of all fit indices for all models with the exception of $\chi^{2}$ (Table 5). The first model explained $55 \%$ of the variance of the dependent variable $\left(R^{2}=0.554\right)$, the second model explained $58 \%$ of the variance of the dependent variable, and the third model explained $43 \%$ of the variance of the dependent variable. Hypotheses were tested using both the statistical significance of the relationship at the 0.05 level, and whether the relationship was positive or negative as hypothesized. In total, 8 of the 12 study hypotheses were supported. Table 5 provides a comparison of within-model relationships between the three models and the results of hypothesis testing. Positive attitudes were not a significant predictor of intention to travel to Cuba within 1 year, but were a significant positive predictor of intention to travel to Cuba within 5 years and 10 years. Negative attitudes were a significant positive predictor of intention to travel to Cuba within 1 year, were not a significant predictor of intention to travel to Cuba within 5 years, and were a significant negative predictor of intention to travel to Cuba within 10 years. Perceived behavioral control was a significant positive predictor of intention to travel to Cuba within 1 year and 5 years, but was not a significant predictor of intention to travel to Cuba within 10 years. Subjective norms were a significant positive predictor of intention to travel to Cuba across all three travel time horizons.

\section{Discussion and Conclusions}

This study sought to examine the predictors of US residents' intention to travel to Cuba across three travel time horizons. Diplomatic relationships between the United States and Cuba are rapidly changing, and the possibility of uninhibited travel between the two countries is now a distinct possibility. If relations thaw to that point, it is likely that the United States will become a major tourism market to Cuba, as it is to other Caribbean destinations. With the potential for increased tourism visitation, tourism organizations large and small seeking to market their goods and services to US residents will need to understand the influences over intentions to travel to Cuba now and into the future (Padilla and McElroy 2007).

This study extends the body of literature on the TPB in two ways. First, both positive and negative attitudes were measured separately, as suggested in previous attitudes literature but rarely applied within tourism (Cacioppo and Berntson 1994). The vast majority of previous studies have measured attitudes through semantic differentials. By splitting attitudes into positive and negative dimensions, research results revealed that having a negative attitude toward a destination does not necessarily reduce one's intention to travel there. Some travelers desire the raw tourism experience provided by these destinations that are not yet homogenized through the forces of globalization. Some tourists go further, seeking out contested destinations. Second, this is the first study within the tourism realm that has measured intention to travel across multiple time horizons. By partitioning intention to travel into three separate time horizons, researchers gain the ability to see how the antecedents to intention to travel change by time horizon. Both of these extensions of the TPB provide valuable information that would otherwise be unknown, and show that predicting intention to travel to a given tourism destination is a complicated task. Further hypothesis testing provided mixed results for the theoretically predicted relationships within the TPB. 
Table 5. Relationships within the TPB Model by Intention to Travel Time Horizon.

\begin{tabular}{|c|c|c|c|c|}
\hline Hypothesized Relationship & $\begin{array}{l}\text { Intention to } \\
\text { Travel Horizon }\end{array}$ & $\begin{array}{l}\text { Standardized } \\
\text { Regression Coefficient }\end{array}$ & $P$ & $\begin{array}{l}\text { Support for } \\
\text { Hypothesis }\end{array}$ \\
\hline \multirow{3}{*}{$\begin{array}{l}\text { Hypotheses Ia-I c: Positive attitudes } \rightarrow \\
\text { Intention to travel to Cuba }(+)\end{array}$} & I year ${ }^{a}$ & .056 & .226 & $\mathrm{~N}$ \\
\hline & 5 years $^{b}$ & .315 & .000 & Y \\
\hline & 10 years $^{c}$ & .310 & .000 & $Y$ \\
\hline \multirow{3}{*}{$\begin{array}{l}\text { Hypotheses } 2 \mathrm{a}-2 \mathrm{c} \text { : Negative attitudes } \rightarrow \\
\text { Intention to travel to Cuba }(-)\end{array}$} & I year & .133 & .000 & $\mathrm{~N}$ \\
\hline & 5 years & -.065 & .108 & $\mathrm{~N}$ \\
\hline & 10 years & -.102 & .034 & $\mathrm{Y}$ \\
\hline \multirow{3}{*}{$\begin{array}{l}\text { Hypotheses } 3 \mathrm{a}-3 \mathrm{c} \text { Perceived behavioral } \\
\text { control } \rightarrow \text { Intention to travel to Cuba }(+)\end{array}$} & I year & .074 & .013 & $Y$ \\
\hline & 5 years & .087 & .003 & $Y$ \\
\hline & 10 years & .067 & .063 & $\mathrm{~N}$ \\
\hline \multirow{3}{*}{$\begin{array}{l}\text { Hypotheses 4a-4c: Subjective norms } \rightarrow \\
\text { Intention to travel to Cuba }(+)\end{array}$} & I year & .724 & .000 & $\mathrm{Y}$ \\
\hline & 5 years & .421 & .000 & $Y$ \\
\hline & 10 years & .322 & .000 & $Y$ \\
\hline
\end{tabular}

Note: CFI = comparative fit index; TLI = Tucker-Lewis Index; RMSEA = root mean square error of approximation; SRMR = standardized root mean square residual.

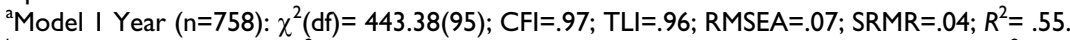

bModel 5 Years $(n=632): \chi^{2}(d f)=469.95(95) ; C F I=.96 ;$ TLI=.95; RMSEA=.08; SRMR=.04; $R^{2}=.58$.

'Model 10 Years $(\mathrm{n}=502): \chi^{2}(\mathrm{df})=4 \mathrm{I} 2.99(95) ; \mathrm{CFI}=.95 ; \mathrm{TLI}=.94 ; \mathrm{RMSEA}=.08 ; \mathrm{SRMR}=.05 ; R^{2}=.43$.

The structural equation models revealed support for 8 of 12 theoretically based study hypotheses. Subjective norms were significant positive predictors of intention to travel to Cuba across all time horizons, as hypothesized. Perceived behavioral control was a significant positive predictor of intentions to travel to Cuba within 1 year and 5 years, but not 10 years. Positive attitudes did not have a significant relationship with intention to travel to Cuba within 1 year, and negative attitudes did have a significant positive relationship with intention to travel to Cuba within 1 year. This finding runs in opposition to the TPB and study hypotheses (Ajzen 1991). The two additional structural equation models revealed that the influence of US residents' attitudes toward Cuba differed by travel time horizon with positive attitudes toward Cuba becoming more important in predicting intention to travel in longer travel time horizons. Negative attitudes were only a significant negative predictor of intention to travel to Cuba in the 10-year travel planning horizon model.

The significant positive relationship between negative attitudes toward Cuba and intention to travel to Cuba within 1 year reveals that some potential travelers may prefer to visit a destination that they perceive to be scary, risky, or uncomfortable. The wants and needs of tourists vary greatly depending on the type of traveler (Plog 2001). While some travelers prefer to have a comfortable, worry-free vacation, others pursue experiences that introduce uncertainty and sometimes even risk (Lepp and Gibson 2008; Williams and Baláž 2015). Travelers seeking to get out of their comfort zone are interested in novel travel and tourism experiences, which, in the era of globalization, are becoming increasingly hard to find. For those tourists, potential travel to Cuba within the near future represents a chance at a truly unique tourism experience that was once "forbidden," at least from the perspective of those living in the United States.

Examined comprehensively, the combination of negative attitudes predicting intent to travel to Cuba within 1 year, and positive attitudes predicting intention to travel to Cuba within 5 years and 10 years indicates that potential travelers may be anticipating the changes to Cuba as a tourism destination as predicted by many in the popular media (Orsi 2015). The perception that Cuba will be changed as a tourism destination if US citizens are allowed to travel there unhindered has been a popular narrative for the past several years. The changes that would likely occur to Cuba if access were allowed would make Cuba a more comfortable destination to those coming to the United States. Such changes could range from small things like an increase in the use and understanding of the English language (Dörnyei and Csizér 2005) to full-scale "McDonaldization" (Zegre et al. 2012). Such changes would inevitably lead travelers seeking risky or forbidden experiences to choose other destinations, and would pave the way for those who see Cuba as enjoyable, worthwhile, and satisfying to then travel there. These findings, while specific to the United States and Cuba, also have merit for other geopolitical revivals. As such, testing a temporal model of TPB with other transnational contexts would be a valued contribution to geopolitical tourism literature.

A closer examination of standardized regression coefficients shows that subjective norms was the strongest predictor of intention to travel to Cuba across all travel time horizons, but its strength decreased as potential travel became farther into the future. In this context, it appears as though the focus on what others think about travel behaviors shrinks as time horizons grow longer. Meanwhile, perceived behavioral control was a weak predictor of intention to travel to 
Cuba across all three travel time horizons. This could be a result of the fact that the travel embargo between Cuba and the United States remains in place. While new policy and travel products have made it easier to travel to Cuba, the perception that Cuba is "off limits" may persist among potential US residents. This may have implications for managers involved in tourism development and marketing for Cuba, who need to recognize the potential barriers to travel that may exist for American visitors. Additional research is necessary to determine whether the differences in these relationships are unique to this study context, or whether they hold true across other geopolitical relationships and "contested destinations."

Tourism organizations including the Cuban Ministry of Tourism, American travel agencies and tour operators, and individual Cuban entrepreneurs renting out a room in their house or running a small residential restaurant should find this information useful (Sanchez and Adams 2008; Hingtgen et al. 2015). The quickly changing business environment in Cuba means an increasing range of organizations are starting to become active in the tourism industry. Findings from this study provide baseline data for those organizations should the US market become open, and should they choose to market to US residents. For those organizations, it would be wise to pursue the adventure travel market (allocentrics) initially, as it is those travelers who are most interested in coming to Cuba within the next year. However, as time passes, those organizations should target more mainstream tourists (midcentrics or psychocentrics) who may be more comfortable with a Cuban tourism product that has shifted to cater to the US market. Depending upon the trajectory of Cuban tourism development in the future, their ability to attract the allocentric market may continue for some time (Butler 1980). This also has implications for the competitive nature of Cuba within the crowded Caribbean market place, which should be explored in future studies. As Cuba's tourism industry evolves, its current competitive appeal could fade once the rough character and edgy reputation sought by allocentrics fades into the safe, sterilized tourism experience sought by psychocentrics. If Cuba is able to preserve the authentic character currently sought by this allocentric market, perhaps they will be able to maintain a sustained competitive advantage against other Caribbean competitors.

There are several important limitations to this research. While it is novel to apply three time horizons to the TPB, a cross-sectional study is not the definitive way to measure intention to travel to a tourism destination at various time periods in the future. The constructs measured in the TPB have been found to change over time, likely meaning that the relationships among them also change. There is also the possibility that though respondents have every intention of visiting the destination 5 or 10 years down the road, life circumstances such as personal health and finances will change. This creates quite a bit of uncertainty as the time horizons are extended out to the 10 -year mark. To address this challenge, it would be valuable to conduct a longitudinal panel study that measured intention to travel at regular intervals. This would enable destination marketers to have a consistent pulse on how the disposition toward the destination is changing. This study also did not measure whether or not individuals actually traveled to Cuba. Further examination of whether intention to travel to Cuba predicts actual travel to Cuba would be beneficial, especially considering that intention has been found to be a stronger predictor of behaviors on a shorter time horizon compared to a longer time horizon (Morwitz 1997). Construal level theory may also help in future explorations of changes in perceptions of destinations over time (Trope, Liberman, and Wakslak 2007). The TPB is just one theoretical framework that seeks to explain how intention to engage in a behavior is formed. In the travel and tourism realm, there are a great deal of other factors that influence destination choice and travel behaviors such as the symbolic image of destination (Ekinci, Sirakaya-Turk, and Preciado 2013; Usakli and Baloglu 2011). Future research should examine these factors using theories such as self-congruity and conspicuous consumption to see which antecedents best explain intention to travel across different time horizons. Specific models for examining image formation, such as those related to destination personality may also help to explain potential tourists' perceptions of Cuba as a tourism destination (Papadimitriou, Apostolopoulou, and Kaplanidou 2015).

This study has revealed the importance of gaining a deeper understanding of the elements which influence perceptions of Cuba and US residents' intention to travel there, including positions on political issues such as the embargo and related travel policies. A deeper knowledge of the potential visitors to Cuba and their expectations for experiences within the country could also yield valuable information for tourism managers in Cuba. Additionally, studies exploring the perceptions of other tourism markets to Cuba (e.g., Canadians) relative to potential influx of US residents would be relevant to the current context. Finally, quantitative research lacks the depth to explain why US residents' attitudes toward Cuba had different influence on intent to visit across different time horizons. Future qualitative research is encouraged to provide a richer explanation of this research finding.

In conclusion, this study provides baseline information about the potential outbound travel market from the United States to Cuba and extends the theory of planned behavior to include multiple travel planning horizons and splitting attitudes into positive and negative constructs. In the short term, those wishing to attract US-based travelers to Cuba would be wise to appeal to those interested in novel or risky experiences. However, it is possible that US residents' perceptions of Cuba will change simply as a result of warming relationships between the two countries. The possibility of change is potentially a good thing for tourism destinations, as there tends to be a much larger 
population of travelers who are interested in "middle of the road" destinations, rather than very risky or very comfortable ones. Continued study of these relationships in the future will be important for the Cuban tourism industry to adapt to political changes if it wishes to capitalize on the potential for outbound travel from the potentially extensive US market. This is now more important than ever as it appears the relationship between the United States and Cuba is in flux with the new presidential administration (Whitefield 2017). Political changes such as these are precisely why the Theory of Planned Behavior has stood the test of time as solid predictor of behavioral intention. Even though American travelers may have the desire to visit Cuba based upon their positive or negative attitudes toward the destination, the political climate may result in negative subjective norms among peers who disapprove of travel to the political opponent or a lack of perceived behavioral control to act upon one's positive disposition toward the destination. With Cuba only 90 miles off the coast of Florida, the TPB provides a good lens for unpacking the range of factors that encourage or discourage residents to travel to a geopolitical adversary.

\section{Declaration of Conflicting Interests}

The author(s) declared no potential conflicts of interest with respect to the research, authorship, and/or publication of this article.

\section{Funding}

The author(s) received no financial support for the research, authorship, and/or publication of this article.

\section{References}

Ajzen, Icek. 1991. "The Theory of Planned Behavior." Organizational Behavior and Human Decision Processes 50 (2): 179-211.

Ajzen, Icek, and B. L. Driver. 1992. "Application of the Theory of Planned Behavior to Leisure Choice." Journal of Leisure Research 24 (3): 207-24.

Alexandrov, Aliosha. 2010 "Characteristics of Single-Item Measures in Likert Scale Format." Electronic Journal of Business Research Methods 8 (1): 1-12.

Armitage, Christopher J., and Mark Conner. 2001. "Efficacy of the Theory of Planned Behaviour: A Meta-Analytic Review." British Journal of Social Psychology 40 (4): 471-99.

Baloglu, Seyhmus. 2000. "A Path Analytic Model of Visitation Intention Involving Information Sources, Socio-Psychological Motivations, and Destination Image." Journal of Travel \& Tourism Marketing 8 (3): 81-90.

Bianchi, Constanza, Sandra Milberg, and Andres Cúneo. 2017. 'Understanding Travelers' Intentions to Visit a Short versus Long-Haul Emerging Vacation Destination: The Case of Chile.” Tourism Management 59 (April): 312-24.

Boley, B. Bynum, Vincent P. Magnini, and Tracy L. Tuten. 2013. "Social Media Picture Posting and Souvenir Purchasing Behavior: Some Initial Findings.” Tourism Management 37 (August): 27-30.
Butler, R. W. 1980. "The Concept of a Tourist Area Cycle of Evolution: Implications for Management of Resources." Canadian Geographer / Le Géographe Canadien 24 (1): 5-12.

Cacioppo, John T., and Gary G. Berntson. 1994. "Relationship between Attitudes and Evaluative Space: A Critical Review, with Emphasis on the Separability of Positive and Negative Substrates." Psychological Bulletin 115 (3): 401-23.

Carnival Cruise Lines. 2016. "What Is Impact Travel." Fathom. https://www.fathom.org/what-is-impact-travel/.

Chen, Feinian, Patrick J. Curran, Kenneth A. Bollen, James Kirby, and Pamela Paxton. 2008. "An Empirical Evaluation of the Use of Fixed Cutoff Points in RMSEA Test Statistic in Structural Equation Models." Sociological Methods \& Research 36 (4): 462-94.

Chen, Joseph S., and Cathy H. C. Hsu. 2001. "Developing and Validating a Riverboat Gaming Impact Scale." Annals of Tourism Research 28 (2): 459-76.

Chen, Mei-Fang, and Pei-Ju Tung. 2014. "Developing an Extended Theory of Planned Behavior Model to Predict Consumers' Intention to Visit Green Hotels." International Journal of Hospitality Management 36:221-30.

Conner, Mark, and Christopher J. Armitage. 1998. "Extending the Theory of Planned Behavior: A Review and Avenues for Further Research." Journal of Applied Social Psychology 28 (15): 1429-64.

Curran, Patrick J., Stephen G. West, and John F. Finch. 1996. "The Robustness of Test Statistics to Nonnormality and Specification Error in Confirmatory Factor Analysis." Psychological Methods 1 (1): 16-29.

Davis, Julie Hirschfeld. 2016. "U.S. Approves 6 Airlines for Direct Flights to Cuba." The New York Times, June 10. http://www. nytimes.com/2016/06/11/business/airlines-cuba-direct.html.

Dolnicar, Sara, and Bettina Grün. 2013. "Validly Measuring Destination Image in Survey Studies." Journal of Travel Research 52 (1): 3-14.

Dörnyei, Zoltán, and Kata Csizér. 2005. "The Effects of Intercultural Contact and Tourism on Language Attitudes and Language Learning Motivation." Journal of Language and Social Psychology 24 (4): 327-57.

Ekinci, Yuksel, Ercan Sirakaya-Turk, and Sandra Preciado. 2013. "Symbolic Consumption of Tourism Destination Brands." Journal of Business Research 66 (6): 711-18.

Finstad, Kraig. 2010. "Response Interpolation and Scale Sensitivity: Evidence against 5-Point Scales." Journal of Usability Studies 5 (3): 104-10.

Fishbein, Martin, and Icek Ajzen. 1977. "Belief, Attitude, Intention, and Behavior: An Introduction to Theory and Research." Philosophy and Rhetoric 10 (2): 130-32.

Fleischer, Andreas, and Christoffer Wåhlin. 2016. "Want to Take a Ride with Me?" Master's Thesis in Business Administration. Jönköping University, Sweden. http://www.diva-portal.se/ smash/get/diva2:934805/FULLTEXT01.pdf (accessed May 8, 2017).

Fleischner, Nicki. 2016. “I Want to See It before It Changes' Is the Wrong Reason to Travel to Cuba." The Huffington Post. http:// www.huffingtonpost.com/nicki-fleischner-/changes-is-wrongreason-to-travel-to-cuba_b_8677232.html.

Gilovich, Thomas, Margaret Kerr, and Victoria H. Medvec. 1993. "Effect of Temporal Perspective on Subjective Confidence." Journal of Personality and Social Psychology 64 (4): 552. 
Hair, Joseph F., William C. Black, Barry J. Babin, and Rolph E. Anderson. 2010. Multivariate Data Analysis: A Global Perspective. Upper Saddle River, NJ: Prentice Hall.

Han, Heesup. 2015. “Travelers' Pro-environmental Behavior in a Green Lodging Context: Converging Value-Belief-Norm Theory and the Theory of Planned Behavior." Tourism Management 47:164-77.

Han, Heesup, Li-Tzang (Jane) Hsu, and Chwen Sheu. 2010. "Application of the Theory of Planned Behavior to Green Hotel Choice: Testing the Effect of Environmental Friendly Activities." Tourism Management 31 (3): 325-34.

Han, Heesup, and Sunghyup Sea Hyun. 2017. "Drivers of Customer Decision to Visit an Environmentally Responsible Museum: Merging the Theory of Planned Behavior and Norm Activation Theory." Journal of Travel \& Tourism Marketing 1-14.

Hannam, Kevin. 2013 "'Shangri-La' and the New 'Great Game': Exploring Tourism Geopolitics between China and India." Tourism Planning \& Development 10 (2): 178-86.

Harman, Harry. 1967. Modern Factor Analysis. Chicago: University of Chicago Press.

Henze, N., and B. Zirkler. 1990. "A Class of Invariant Consistent Tests for Multivariate Normality." Communications in Statistics - Theory and Methods 19 (10): 3595-617.

Hingtgen, N., Carol Kline, Luci Fernandes, and Nancy Gard McGehee. 2015. "Cuba in Transition: Tourism Industry Perceptions of Entrepreneurial Change." Tourism Management 50 (October): 184-93.

Holan, Pablo Martin de, and Nelson Phillips. 1997. "Sun, Sand, and Hard Currency." Annals of Tourism Research 24 (4): 777-95.

Hsieh, Chi-Ming, Sung Hee Park, and Regina McNally. 2016. "Application of the Extended Theory of Planned Behavior to Intention to Travel to Japan among Taiwanese Youth: Investigating the Moderating Effect of Past Visit Experience." Journal of Travel \& Tourism Marketing 33 (5): 717-29.

Hsu, Cathy H. C., and Songshan (Sam) Huang. 2012. "An Extension of the Theory of Planned Behavior Model for Tourists." Journal of Hospitality \& Tourism Research 36 (3): 390-417.

$\mathrm{Hu}$, Li-tze, and Peter M. Bentler. 1999. "Cutoff Criteria for Fit Indexes in Covariance Structure Analysis: Conventional Criteria versus New Alternatives." Structural Equation Modeling: A Multidisciplinary Journal 6 (1): 1-55.

Jacobsen, Jens Kr. Steen, and Ana María Munar. 2012. "Tourist Information Search and Destination Choice in a Digital Age." Tourism Management Perspectives 1 (January): 39-47.

Jalilvand, Mohammad Reza, and Neda Samiei. 2012. "The Impact of Electronic Word of Mouth on a Tourism Destination Choice: Testing the Theory of Planned Behavior (TPB)." Internet Research: Electronic Networking Applications and Policy 22 (5): 591-612.

Kaplan, S., Francesco Manca, Thomas Nielsen, and Carlo Prato. 2015. "Intentions to Use Bike-Sharing for Holiday Cycling: An Application of the Theory of Planned Behavior." Tourism Management 47:34-46.

Kjeldsen, Anders, and Rasmus Pedersen. 2016. “Airbnb: Undersøgelse af danskeres intention om at benytte Airbnb fremfor hoteller i storbyer" [Investigating Danes' intention to use Airbnb rather than hotels in big cities]. Master's thesis, Aarhus University, Denmark. http://pure.au.dk/portal-asb-student/en/studentprojects/airbnb(d3525752-462d4c9b-bef5-84426ea7434f).html (accessed May 8, 2017).
Kline, Rex B. 2010. Principles and Practice of Structural Equation Modeling, 3rd ed. New York: Guilford.

Lam, Terry, and Cathy H. C. Hsu. 2004. "Theory of Planned Behavior: Potential Travelers from China." Journal of Hospitality \& Tourism Research 28 (4): 463-82.

Lam, Terry, and Cathy H. C. Hsu. 2006. "Predicting Behavioral Intention of Choosing a Travel Destination." Tourism Management 27 (4): 589-99.

Lee, Myong Jae, and Ki-Joon Back. 2008. “Association Meeting Participation: A Test of Competing Models." Journal of Travel Research 46 (3): 300-10.

Lepp, Andrew, and Heather Gibson. 2008. "Sensation Seeking and Tourism: Tourist Role, Perception of Risk and Destination Choice." Tourism Management 29 (4): 740-50.

Liberman, Nira, Michael D. Sagristano, and Yaacov Trope. 2002. "The Effect of Temporal Distance on Level of Mental Construal." Journal of Experimental Social Psychology 38 (6): 523-34.

MacCallum, Robert C., Michael W. Browne, and Hazuki M. Sugawara. 1996. "Power Analysis and Determination of Sample Size for Covariance Structure Modeling." Psychological Methods 1 (2): 130-49.

Madden, Thomas J., Pamela Scholder Ellen, and Icek Ajzen. 1992. "A Comparison of the Theory of Planned Behavior and the Theory of Reasoned Action." Personality and Social Psychology Bulletin 18 (1): 3-9.

Mayer, William G. 2001. "Trends: American Attitudes toward Cuba." Public Opinion Quarterly 65 (4): 585-606.

McDonald, Roderick P., and Moon-Ho Ringo Ho. 2002. "Principles and Practice in Reporting Structural Equation Analyses." Psychological Methods 7 (1): 64-82.

Mecklin, Christopher J., and Daniel J. Mundfrom. 2004. "An Appraisal and Bibliography of Tests for Multivariate Normality." International Statistical Review 72 (1): 123-38.

Morwitz, Vicki. 1997. "Why Consumers Don't Always Accurately Predict Their Own Future Behavior.” Marketing Letters 8 (1): 57-70.

Norman, Paul, Mark Conner, and Russell Bell. 1999. "The Theory of Planned Behavior and Smoking Cessation." Health Psychology 18 (1): 89-94.

Nunkoo, Robin, and Kevin Kam Fung So. 2016. "Residents' Support for Tourism Testing Alternative Structural Models." Journal of Travel Research 55 (7): 847-61.

Orsi, Peter. 2015. "Foreign Tourists Are Flocking to Visit Cuba before the Americans Move in and Ruin It." Business Insider, March 23. http://www.businessinsider.com/tourists-want-tovisit-cuba-before-americans-ruin-it-2015-3.

Padilla, Art, and Jerome L. McElroy. 2007. "Cuba and Caribbean Tourism after Castro." Annals of Tourism Research 34 (3): 649-72.

Papadimitriou, Dimitra, Artemisia Apostolopoulou, and Kyriaki Kaplanidou. 2015. "Destination Personality, Affective Image, and Behavioral Intentions in Domestic Urban Tourism." Journal of Travel Research 54 (3): 302-15.

Plog, Stanley C. 2001. "Why Destination Areas Rise and Fall in Popularity: An Update of a Cornell Quarterly Classic." Cornell Hotel and Restaurant Administration Quarterly 42 (3): 13-24.

Podsakoff, Philip M., Scott B. MacKenzie, Jeong-Yeon Lee, and Nathan P. Podsakoff. 2003. "Common Method Biases in Behavioral Research: A Critical Review of the Literature and 
Recommended Remedies." Journal of Applied Psychology 88 (5): 879-903.

Quintal, Vanessa Ann, Julie Anne Lee, and Geoffrey N. Soutar. 2010. "Risk, Uncertainty and the Theory of Planned Behavior: A Tourism Example.” Tourism Management 31 (6): 797-805.

Ramos, Annie R., and Catherine E. Shoichet. 2016. "Historic U.S. Cruise Docks in Havana, Cuba." CNN, May 2. http://www.cnn. com/2016/05/02/travel/us-cuba-cruise/index.html.

Rampersad, Indira. 2014. "The Anti-Cuban Embargo Movement in the United States." Peace Review 26 (3): 402-11.

Raubenheimer, J. 2004. "An Item Selection Procedure to Maximise Scale Reliability and Validity." SA Journal of Industrial Psychology 30 (4): 59-64.

Romeu, Rafael. 2014. "The Vacation Is Over: Implications for the Caribbean of Opening U.S.-Cuba Tourism." Economía 14 (2): $1-27$.

Rosseel, Yves. 2012. "Lavaan: An R Package for Structural Equation Modeling." Journal of Statistical Software 48 (2): $1-36$.

Sanchez, Peter M., and Kathleen M. Adams. 2008. "The JanusFaced Character of Tourism in Cuba." Annals of Tourism Research 35 (1): 27-46.

Schwartz, Rosalie. 1997. Pleasure Island: Tourism and Temptation in Cuba. Lincoln: University of Nebraska Press.

Sparks, Beverley. 2007. "Planning a Wine Tourism Vacation? Factors That Help to Predict Tourist Behavioural Intentions." Tourism Management 28 (5): 1180-92.

Stylos, Nikolaos, Chris A. Vassiliadis, Victoria Bellou, and Andreas Andronikidis. 2016. "Destination Images, Holistic Images and Personal Normative Beliefs: Predictors of Intention to Revisit a Destination." Tourism Management 53 (April): 40-60.

Telegraph. 2016. "Destinations: 14 Sights to Catch before Cuba Changes Forever." The Telegraph, August 30. http://www.telegraph.co.uk/travel/destinations/caribbean/cuba/galleries/14sights-to-catch-before-Cuba-changes-forever/.

Tham, Aaron, Glen Croy, and Judith Mair. 2013. "Social Media in Destination Choice: Distinctive Electronic Word-of-Mouth Dimensions." Journal of Travel \& Tourism Marketing 30 (1/2): 144-55.

Trope, Yaacov, Nira Liberman, and Cheryl Wakslak. 2007. "Construal Levels and Psychological Distance: Effects on Representation, Prediction, Evaluation, and Behavior." Journal of Consumer Psychology 17 (2): 83-95.

US Embassy. 2016. “Traveling to Cuba.” http://Havana.usinterestsection.gov//Travelling_cuba.html. http://havana.usembassy. gov/travelling_cuba.html (accessed April 26, 2017).

Usakli, Ahmet, and Seyhmus Baloglu. 2011. "Brand Personality of Tourist Destinations: An Application of Self-Congruity Theory." Tourism Management 32 (1): 114-27.

Webster, Craig, and Dallen J. Timothy. 2006. "Travelling to the 'Other Side': The Occupied Zone and Greek Cypriot Views of Crossing the Green Line." Tourism Geographies 8 (2): 162-81.

White House. 2016. "Charting a New Course on Cuba." Whitehouse. gov. https://www.whitehouse.gov/issues.foreign-policy/cuba.

Whitefield, Mimi. 2015. "Poll of Cuban-Americans Shows Support for New Cuba Policies Growing." Miami Herald, April 1. http://www.miamiherald.com/news/nation-world/world/americas/cuba/article17056742.html.
Whitefield, Mimi. 2017. “As Cuban Tourism Booms, U.S. Travel Companies Wonder: What Will Trump Do?" Miamiherald. http://www.miamiherald.com/news/nation-world/world/americas/cuba/article126181259.html (accessed May 18, 2017).

Williams, Allan M., and Vladimír Baláž. 2015. "Tourism Risk and Uncertainty: Theoretical Reflections." Journal of Travel Research 54 (3): 271-87.

World Bank. 2016. "International Tourism, Number of Arrivals." http://data.worldbank.org/indicator/ST.INT.ARVL.

World Travel \& Tourism Council. 2016. "Travel and Tourism Economic Impact 2016: Cuba." http://www.wttc.org/-/media/ files/reports/economic\%20impact\%20research/countries $\% 20$ 2016/cuba2016.pdf.

Yamada, Naoko, and Yao-Yi Fu. 2012. "Using the Theory of Planned Behavior to Identify Beliefs Underlying Visiting the Indiana State Museum." Journal of Travel \& Tourism Marketing 29 (2): 119-32.

Ye, Sheng, Geoffrey Soutar, Joanne Sneddon, and Julie A. Lee. 2017. "Personal Values and the Theory of Planned Behaviour: A Study of Values and Holiday Trade-offs in Young Adults." Tourism Management 62:107-9.

Zegre, Sera J., Mark D. Needham, Linda E. Kruger, and Randall S. Rosenberger. 2012. "McDonaldization and Commercial Outdoor Recreation and Tourism in Alaska." Managing Leisure 17 (4): 333-48.

\section{Author Biographies}

Evan J. Jordan is an assistant professor in the School of Community Resources and Development at Arizona State University. His research focuses on tourism policy, planning, development, and impacts, and he has a particular interest in the area of psychological impacts of tourism development. His scholarly goal is to examine how tourism affects the quality of life of host community residents and determine best practices for the tourism development process that promote sustainability tourism communities.

B. Bynum Boley is an assistant professor of Natural Resources, Recreation and Tourism within the Warnell School of Forestry and Natural Resources at the University of Georgia. His research interests focus on sustainable tourism with special attention to how the unique natural and cultural resources of communities can be protected, packaged and marketed to jointly increase sustainability, resident quality of life and a community's competitiveness as a tourism destination.

Whitney Knollenberg is an assistant professor in the Department of Parks, Recreation, and Tourism Management at North Carolina State University. Her research focuses on political leadership in tourism, as well as multiple aspects of sustainable tourism development, including the roles of power and partnerships in the planning process.

Carol Kline is an associate professor of Hospitality and Tourism Management at Appalachian State University in the Department of Management. Her research interests focus broadly on tourism planning and development and tourism sustainability, but cover a range of topics such as foodie segmentation, craft beverages, agritourism, wildlife-based tourism, animal ethics in tourism, tourism entrepreneurship, niche tourism markets, and tourism impacts to communities. 